\title{
Grupo de Pesquisa Informática Aplicada IFRS - Campus Porto Alegre
}

\author{
Evandro M. Miletto ${ }^{1}$, André Peres ${ }^{1}$, Marcelo Schmitt ${ }^{1}$, \\ Claudimir Zavalik ${ }^{2}$, Helena Lima ${ }^{3}$, Luiz Mazzei ${ }^{3}$ \\ ${ }^{1}$ IFRS - Campus Porto Alegre \\ Av Cel Vicente, 281 - Centro - 90.030-041 - Porto Alegre - RS - Brazil \\ \{evandro.miletto, andre.peres,marcelo.schmitt\}@poa.ifrs.edu.br \\ ${ }^{2}$ ZAVATEC Informática \\ Rua dos Andradas, 1137/806 - Centro, Porto Alegre - RS - Brasil \\ claudimir@zavatec.com.br
}

${ }^{3}$ Colégio de Aplicação (UFRGS)

Av. Bento Gonçalves, 9500 - Prédio 43815 - 91501-970 - Porto Alegre - RS - Brasil

eu.helena.l@gmail.com, luiz.mazzei@gmail.com

O Grupo de Pesquisa Informática Aplicada ${ }^{1}$ do Instituto Federal de Educação, Ciência e Tecnologia do Rio Grande do Sul - IFRS - Campus Porto Alegre desenvolve projetos e pesquisas de caráter interdisciplinar e de natureza aplicada, alinhadas à filosofia de criação dos Institutos Federais, regulamentados pela Lei 11.892/20082 2 . Dentro da sua linha de pesquisa Tecnologia da Informação Aplicada à Educação, o grupo têm investigado metodologias, técnicas e ferramentas computacionais para serem aplicadas à educação de uma forma geral. Um dos movimentos mais importantes e recentes para a comunidade da Informática na Educação foi a aprovação de 03 projetos de pesquisa na Chamada CNPq 094/2013 $3^{3}$. Os projetos Criação de Objetos Reais de Aprendizagem Utilizando os Conceitos de Internet das Coisas, Impressoras 3D, Hardware e Software Livres - em convênio com a empresa Zavatec Informática, Learning Analytics Desenvolvimento de Ferramenta para Coleta, Medição, Análise e Relatório de Dados Educacionais - em convênio com o CINTED/UFRGS e Criação Musical Coletiva na Web - em convênio com o Colégio de Aplicação da UFRGS, exploram novas possiblidades com objetos de aprendizagem físicos, abertos, impressos em 3D, desenvolvem tecnologia que poderá ser utilizada em conjunto com ambientes virtuais de aprendizagem nas diversas instituições de ensino e produzem um sistema na Web para criação musical coletiva por leigos em música, visando inclusão social através da experimentação musical, respectivamente. Por fim, uma ação de destaque do grupo Informática Aplicada é a submissão ao APCN/CAPES - 2014 do primeiro Mestrado Profissional em Informática na Educação público da Região sul do Brasil, apoiado pelo PGIE-UFRGS, para formar um perfil de egressos capazes de propor, gerenciar e fomentar o desenvolvimento de pesquisa aplicada e inovação tecnológica na região em que atua.

\footnotetext{
${ }^{1}$ Ver detalhes do Grupo em http://www.inf.poa.ifrs.edu.br/?page_id=11

${ }^{2}$ Cria os Institutos Federais: disponível em http://www.planalto.gov.br/ccivil_03/_ato2007-2010/2008/lei/111892.htm

${ }^{3}$ Apoio a Projetos Cooperativos de Pesquisa Aplicada e de Extensão Tecnológica http://resultado.cnpq.br/1098315380873451
} 